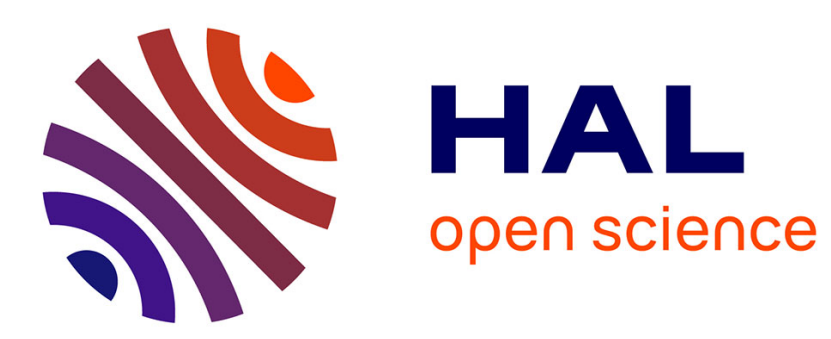

\title{
Influence of damage on pore size distribution and permeability of rocks
}

\author{
Chloé Arson, Jean-Michel Pereira
}

\section{To cite this version:}

Chloé Arson, Jean-Michel Pereira. Influence of damage on pore size distribution and permeability of rocks. International Journal for Numerical and Analytical Methods in Geomechanics, 2013, 37 (8), pp.810-831. 10.1002/nag.1123 . hal-00946106

\section{HAL Id: hal-00946106 \\ https://hal-enpc.archives-ouvertes.fr/hal-00946106}

Submitted on 8 May 2019

HAL is a multi-disciplinary open access archive for the deposit and dissemination of scientific research documents, whether they are published or not. The documents may come from teaching and research institutions in France or abroad, or from public or private research centers.
L'archive ouverte pluridisciplinaire HAL, est destinée au dépôt et à la diffusion de documents scientifiques de niveau recherche, publiés ou non, émanant des établissements d'enseignement et de recherche français ou étrangers, des laboratoires publics ou privés. 


\title{
Influence of Damage on Pore Size Distribution and Permeability of Rocks
}

\author{
Chloé ARSON ${ }^{1, *}$, Jean-Michel PEREIRA ${ }^{2}$ \\ 1 Zachry Department of Civil Engineering, Texas A $B M$ University, USA \\ 2 Université Paris-Est, Laboratoire Navier, Ecole des Ponts ParisTech, France
}

\begin{abstract}
SUMMARY
The model proposed in this paper relates permeability to porosity measurements that can easily be performed in the laboratory. The Pore Size Distribution (PSD) curve is updated with strains and damage. The updated volumetric fractions of natural pores and cracks are introduced in the expression of permeability. Contrary to classical permeability models based on PSD integrations, the model proposed in this paper accounts for possible changes in the porosity modes: one mode for undamaged samples, and two modes for cracked samples. The proposed approach also accounts for varying states of damage, as opposed to classical fracture network models, in which the cracks pattern is fixed. The only material parameters that are required to describe the microstructure are the lower and upper bounds of the pores size for both natural pores and cracks. All the other PSD parameters involved in the model are related to macroscopic parameters that can easily be determined in the laboratory, such as the initial void ratio. The framework proposed in this paper can be used in any damage constitutive model to determine the permeability of a brittle porous medium. Drained triaxial compression tests have been simulated. Before cracks initiation, permeability decreases while the larger natural pores are getting squeezed. After the occurrence of damage, permeability grows due to the increase of cracks density. The model performs well to represent the influence of the confining pressure on damage evolution and permeability variations. Copyright (c) 2000 John Wiley \& Sons, Ltd.
\end{abstract}

KEY WORDS: Poromechanics, Continuum Damage Mechanics, Pore Size Distribution curve, Permeability, Rock microstructure

\section{INTRODUCTION}

Most of the research on rock mechanics is motivated by societal needs such as energy production, energy storage and waste confinement, in which the permeability of the host rock plays a critical role. Performance, reliability and safety are the key issues in such geotechnical

*Correspondence to: Chloé Arson

CE/TTI building, room 808-R

3136 TAMU

College Station, TX 77843-3136, USA

Tel: 979-862-5659

Mail: carson@civil.tamu.edu 
projects, related to oil and gas extraction [10, 32, 67], geothermal systems [11, 39], pressurized gas storage $[18,20,27,56]$, carbon dioxide sequestration $[5,61]$ or nuclear waste disposals $[8,9,25,43,58]$. Permeability depends on the geometry of the connected porous network. The latter depends on the alteration of rock microstructure: deformation and micro-cracking change the geometry of the porous network with no mass transfer, whereas diffusion creep, dissolution and precipitation are associated to species phase changes [65]. Chemical reactions are caused by solute advection and diffusion, which are facilitated by heat transfer and porefluid mixing [62]. With the increasing demand of natural minerals, ore forming mechanisms have become a priority research topic. Understanding how thermo-hydro-chemical processes influence porosity and bulk permeability can help in finding new mineral deposits in the deep Earth $[63,64,66]$. The present paper focuses on reversible and irreversible changes operated on the porous network without mass transfer. The considered porous network is made of cracks (due to damage) and natural pores (located in the undamaged matrix). Relating the rock microstructure to the rock macroscopic behavior (e.g. stiffness tensor, permeability, thermal conductivity) is a long standing problem of constitutive modeling. However, it has gained a large interest in recent years because of important technical advances, such as Scanning Electron Microscopy (SEM) [7, 42] and X-ray tomography [37, 44]. The aim of this research work is to relate the evolution of deformation and damage to permeability changes. The approach consists in determining the effects of deformation and damage on the Pore Size Distribution (PSD) curve of the material. Simple and common assumptions are made to link the PSD equation to the expression of permeability. The PSD curve can easily be determined in the laboratory for any state of irreversible deformation and damage, by resorting to Mercury Intrusion Porosimetry (MIP) for instance. One advantage of the method adopted in this paper is that the model can easily be calibrated and validated from simple laboratory measurements.

Hagen-Poiseuille equation and Darcy's law relate the intrinsic permeability of a porous material to its porosity. The latter can be determined by integrating the equation of the Pore Size Distribution curve. Therefore, the Pore Size Distribution curve provides essential macroscopic parameters. The first models based on the knowledge of the PSD curve focused on unimodal porous media. Garcia-Bengochea et al. [24] explained several approaches to determine the relationship between the porosity and the intrinsic permeability of a granular material. Van Genuchten [59] used a Bell-shaped Pore Size Distribution curve to relate the degree of saturation to capillary pressure on the one hand, and to the material relative permeability on the other hand. More recent studies resort to the PSD curve to determine the retention and permeability properties of bimodal porous media $[49,50,51,53]$. However, these studies deal with undamaged materials. Several permeability models have been proposed to account for damage and healing in salt rock [13, 54]. Cosenza and Ghoreychi [17] have modeled the influence of water on the chemical potential of salt rock to predict the permeability reduction induced by brine precipitation. They have also studied the "dissolution - transport - crystallization" process, by which crushed crystal joints form a gouge that is transported to the cracks network. The particles crystallize in the cracks, which reduces permeability. In salt rock, damage is associated to an increase of volumetric strains, as opposed to isochoric creep strains. Olivella and Gens [45] proposed a dilatancy model to predict permeability changes in cracked porous media. The fact that damage-induced strains are volumetric does not imply that damage itself is isotropic. The main limitation of the permeability models based on dilatancy is that they are unable to predict flow paths that may form in the Excavation Damaged Zone. A few phenomenological models based on Continuum Damage Mechanics account for 
the effect of cracking on permeability changes. In anisotropic damage models, it is usually assumed that cracks permeability adds to the permeability of the undamaged rock matrix. The flow induced by damage is often considered to occur in the cracks planes, which makes it possible to compute cracks permeability from the cubic law [4, 55]. Maleki and Pouya [40, 41] have proposed an original approach, in which the cracks permeability tensor is projected in the principal base of a fabric tensor. Fracture network flow models account for the cracks locations, lengths, apertures and orientations [38]. In multimodal models [21], natural pores and cracks are assumed to connect and to form a unique porous network. The pore pressure of the fluid is thus assumed to be homogeneous in the Representative Elementary Volume (REV). In multi-continua models [60], the natural porous network and the cracks network are assumed to drive fluid flows separately, but not always independently. Each continuum (natural pores on the one hand, cracks on the other hand) is thus characterized by its own pressure head. Richards equations are coupled by coefficients that quantify the fluid exchanges between the natural pores and the cracks. In all fractures network models, one of the challenges consists in determining the equivalent flow properties of a material element from the parameters of each network [46, 48]. The REV size is an important assumption of the model, because permeability is scale-dependent $[26,69]$. One of the main limitations of the fracture network models lies in the difficulty to assess internal length parameters and percolation thresholds. Moreover, such models generally do not account for the deformation of the solid skeleton (rigid matrix), nor for the evolution of damage (fixed cracks configuration).

The proposed permeability model can be coupled to any damage model used to predict damage evolution and the effect of cracking on the stiffness tensor. In this paper, simulations are performed assuming that cracking depends on tensile strains. The outline of the mechanical damage model is presented in Section 2, along with the main constitutive equations of the permeability model. Parameters are introduced to define the equations of the Pore Size Distribution curves. Permeability is expressed with functions depending on PSD integrals. The details of the algorithm used to update the PSD curve with damage and strains are provided in Section 3. The model predictions are studied through triaxial compression tests simulated in drained conditions. The material chosen for these tests is granite, for which it was possible to resort to published experimental results to calibrate and validate the mechanical damage model used in this study. The evolution of the model parameters and variables is thoroughly studied in section 4. In Section 5, parameters are calibrated, and the sensitivity of the model to the confining pressure is analyzed.

\section{MODEL OUTLINE}

\subsection{Mechanical Damage Model}

The Representative Elementary Volume (REV) considered in this study is made of a solid skeleton and of a porous network. The latter includes natural pores, which are present in the reference state, and cracks. Damage is relative, and any state of damage can virtually be considered as the reference state. In this study, the reference state is the state of the material before cracking is generated by the loading applied in the experiment (or simulated in the numerical computation). In reality, rock contains micro-cracks that add to the porosity of the intact rock minerals. The latter is called "porosity of the intact matrix" throughout the paper. 
It is assumed that micro-cracks existing in pristine rock are small and scarce enough to be considered part of the matrix porous network. As a result, the elastic parameters measured in the initial state of the laboratory tests simulated in the sequel are said to be "undamaged". The reference state is actually defined as the undamaged state, when the REV contains no open crack. In phenomenological models, damage is represented indirectly, by quantifying the effects of cracking on stiffness, strains and permeability. In microscopic models, damage is assessed by measuring the number and volume of cracks in the REV. The definition of damage thus depends on the modeling approach adopted [47]. In the following, damage is defined as the spectral decomposition of the second-order crack density tensor [34]:

$$
\boldsymbol{\Omega}=\sum_{k=1}^{3} d^{k} \boldsymbol{n}^{\boldsymbol{k}} \otimes \boldsymbol{n}^{\boldsymbol{k}}
$$

where the principal directions of damage are given by the vectors $\boldsymbol{n}^{\boldsymbol{k}}$, which are normal to the three principal crack planes. $d^{k}$ is the volumetric fraction of the k-th family of cracks in the REV. The aim of this research work is to model the evolution of the porous network with deformation and damage, and to assess the corresponding impact on permeability. The idea is to propose a theoretical framework that will be easy to plug into any damage constitutive model based on Continuum Damage Mechanics. To illustrate the capabilities of the model proposed for damaged permeability, simulations have been done by using a simple mode I failure model inspired from the works of Dragon and Halm [22]. Total strains are decomposed into [1]:

$$
\epsilon=\epsilon^{e l}+\epsilon^{e d}+\epsilon^{i d}
$$

where $\epsilon^{e l}$ is the purely elastic deformation, that would be obtained if the stiffness tensor were undamaged. $\epsilon^{e d}$ is the additional elastic deformation induced by the degradation of stiffness with cracking. $\boldsymbol{\epsilon}^{\boldsymbol{i d}}$ is the damage residual strain, which accounts for the presence of remaining open cracks after unloading. The definition of the three components of deformation is illustrated in Fig.1.

The stress-strain relationship simply writes:

$$
\boldsymbol{\sigma}=\boldsymbol{D}(\boldsymbol{\Omega}): \boldsymbol{\epsilon}^{e}
$$

in which $\boldsymbol{\epsilon}^{e}=\boldsymbol{\epsilon}^{e l}+\boldsymbol{\epsilon}^{e d} . \boldsymbol{D}(\boldsymbol{\Omega})$ is the stiffness tensor in the current state of damage $\left(\Omega_{2}\right.$ in Fig. 1 ). The damaged elasticity tensor $\boldsymbol{D}(\boldsymbol{\Omega})$ is computed by applying the principle of equivalence between the deformation energy of a damaged REV subjected to the real stress field $\boldsymbol{\sigma}$ and the deformation energy of an undamaged REV subjected to the effective stress field $\widetilde{\boldsymbol{\sigma}}$ [29]. The effective stress is defined by resorting to the operator of Cordebois and Sidoroff [15]. When a tensile loading generates cracks, it is expected that a bare unloading will not suffice to close the cracks. The remaining cracks openings originate residual damage strains (equation 1). The compressive stress $\left(\boldsymbol{\sigma}^{\boldsymbol{R}}\right)$ that would be necessary to close the remaining open cracks is assumed to be parallel to damage:

$$
\boldsymbol{\sigma}^{\boldsymbol{R}}=-g \boldsymbol{\Omega}
$$

The damage criterion indicates that damage grows with tensile strains $[14,22,31]$ :

$$
f_{d}\left(\boldsymbol{\Omega}, \boldsymbol{\epsilon}^{+}\right)=\sqrt{\frac{1}{2}\left(g \boldsymbol{\epsilon}^{+}\right):\left(g \boldsymbol{\epsilon}^{+}\right)}-C_{0}-C_{1} \boldsymbol{\delta}: \boldsymbol{\Omega}
$$




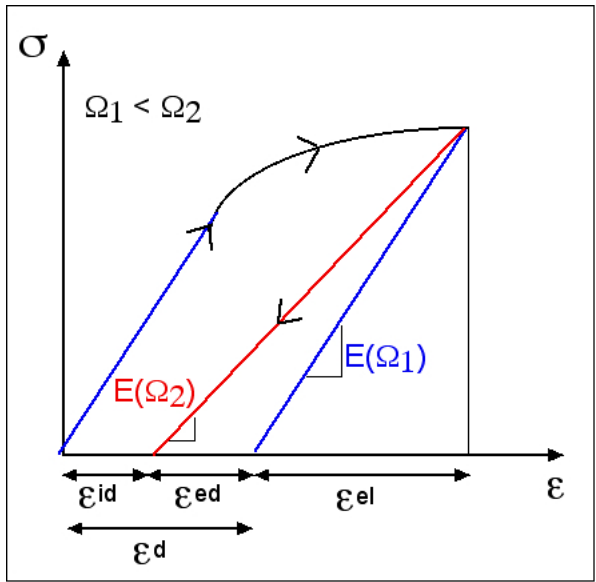

Figure 1. Definition of the components of strains. In this illustrative case, $\Omega_{1}$ is the amount of damage in the reference state.

in which $\delta$ is the second-order identity tensor. $g$ is the resistance to crack closure (Equation 4). $C_{0}$ is the initial damage threshold, and $C_{1}$ controls cracks growth with cumulated damage. The damage flow rule is assumed to be associate.

\subsection{Pore Size Distribution Curve}

Natural pores are expected to change according to the deformation experienced by the REV. In addition to the natural pores, damaged materials contain cracks that form another part of the porous network. Observations done on clay rock [40] show that it is reasonable to assume that the typical size of the cracks is at least one order of magnitude larger than the typical size of natural pores. In a damaged porous medium, the Pore Size Distribution curve thus shows two distinct modes (Fig. 2.b,c). In intact (undamaged) states, the PSD curve is characterized by the natural mode only (Fig. 2.a). If the rock is considered as a cracked solid, the PSD curve also shows a unique mode (Fig. 2.d). The PSD curve is obtained by an experimental technique (Mercury Intrusion Porosimetry for instance) which makes it possible to measure connected porosity only. The permeability model presented in the sequel is based on the knowledge of the PSD curve for any state of deformation and damage. Therefore, two assumptions are made:

1. the natural porosity refers to the connected natural porosity (classical assumption),

2. cracks may be not connected to each other, but cracks are connected to the natural porous network (assumption supported by Maleki and Maleki and Pouya [40, 41]), so that damage contributes to an increase of fluid flow from the initiation of cracking.

The experimental determination of the PSD curve is based on an isotropic flow test. Each pore is seen as a tube conveying the flow. That is the reason why the porous network is modeled as a bundle of parallel cylinders of equal length, characterized by different radii [24]. By construction, the model proposed in the sequel is thus based on a simple geometric representation of the porous network: both natural pores and cracks are assumed to be 


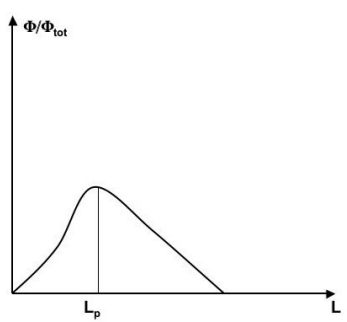

a.

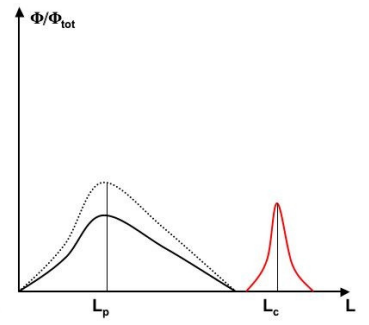

b.

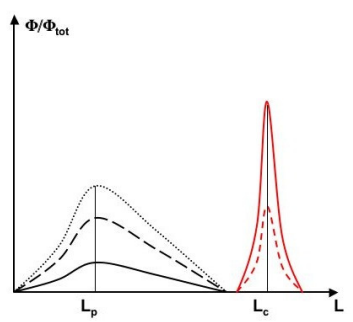

c.

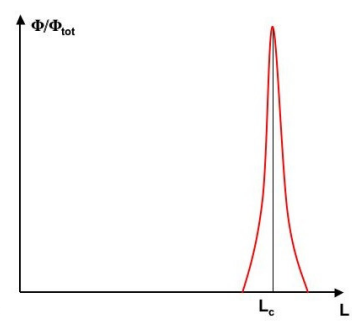

d.

Figure 2. Pore Size Distribution curve evolving with deformation and damage. a. Intact (undamaged) material. b,c. Damaged material. d. Cracked solid.

cylinders. This is actually the same assumption as the one used to interpret raw data from Mercury Intrusion Porosimetry tests. Considering a flow model in one dimension, the length of the cylinders is equal to the length of the REV in the direction parallel to the flow. The pore "size" distribution is thus only characterized by a radius distribution. This approach makes it possible to get a simple and straightforward expression for the "isotropic" permeability (as explained in the following paragraph). The Pore Size Distribution curve of the REV is obtained by the juxtaposition of the PSD curve corresponding to radius distribution of the natural pores with the PSD curve corresponding to the radius distribution of the cracks. Natural pore sizes are assumed to follow a Bell-shaped distribution (Fig. 3.a), like in the classical model proposed by Van Genuchten [59]. The corresponding log-normal probability density function (pdf) writes:

$$
p_{p}(r)=\left\{\begin{array}{l}
\frac{1}{s \sqrt{2 \pi}} \exp \left(-\frac{(r-m)^{2}}{2 s^{2}}\right) \quad \text { if } \quad r_{\min }^{p} \leq r \leq r_{\max }^{p} \\
0 \quad \text { otherwise }
\end{array}\right.
$$

$m$ and $s$ are the mean and the standard deviation of the probability density function, respectively. $r_{\min }^{p}$ and $r_{\max }^{p}$ are respectively the minimum and maximum values that can be taken by the radius of the natural pores. Using the definition of the probability density function $p_{p}$ [23], we have:

$$
\int_{-\infty}^{\infty} p_{p}(r) d r=1 \Rightarrow \int_{r_{\min }^{p}}^{r_{\max }^{p}} p_{p}(r) d r \approx 1
$$

In other words, $m$ and $s$ are adjusted in such a way that the integral of the pdf $p_{p}$ over the interval $\left[r_{\min }^{p}, r_{\max }^{p}\right]$ be still equal to unity. In the same way, by definition of the expectancy (or mean value) $m$ :

$$
\int_{-\infty}^{\infty} p_{p}(r) r d r=m \Rightarrow \int_{r_{\min }^{p}}^{r_{\max }^{p}} p_{p}(r) r d r \approx m
$$

Assuming that the total number of natural pores in the REV is equal to $N_{p}$, the number of natural pores of size $r$ is equal to $\alpha_{p}(r)=N_{p} p_{p}(r)$. Each pore is considered as a cylinder. Therefore, the "area frequency" of the natural pores of radius $r$ is: $\alpha_{p}(r) \pi r^{2}$ [24]. The length of the REV in the direction parallel to the flow is considered equal to unity (unit REV). As a 
result, the "volumetric frequency" of the natural pores of radius $r$ is also equal to $\alpha_{p}(r) \pi r^{2}$, and the volume occupied by the natural pores in the REV $\left(V_{p}\right)$ can be computed as follows:

$$
V_{p}=\int_{r_{\min }^{p}}^{r_{\max }^{p}} \alpha_{p}(r) \pi r^{2} d r=\pi N_{p} \int_{r_{\min }^{p}}^{r_{\max }^{p}} p_{p}(r) r^{2} d r
$$

Following the choice of Maleki [40], it is assumed that the sizes of the radii of the cracks follow an exponential law (Fig. 3.b). These radii correspond to the cracks apertures in penny-shaped cracks models. The corresponding probability density function $\left(p_{c}\right)$ writes:

$$
p_{c}(r)=\left\{\begin{array}{l}
\frac{1}{\lambda_{c}} \exp \left(-\frac{r}{\lambda_{c}}\right) \quad \text { if } \quad r_{\text {min }}^{c} \leq r \leq r_{\max }^{c} \\
0 \text { otherwise }
\end{array}\right.
$$

$r_{\min }^{c}$ and $r_{\max }^{c}$ are the minimum and maximum values that can be taken by the cracks radius. $\lambda_{c}$ is the characteristic cracks length. $\lambda_{c}$ is equal to both the mathematical expectancy and the standard deviation of the probability density function $p_{c}$ [23]. Following the same approach as for natural pores, the value of $\lambda_{c}$ is adjusted to the bounds $r_{\min }^{c}$ and $r_{\max }^{c}$ to satisfy:

$$
\int_{0}^{\infty} p_{c}(r) r d r=\lambda_{c} \Rightarrow \int_{r_{\min }^{c}}^{r_{\max }^{c}} p_{c}(r) r d r \approx \lambda_{c}
$$

Noting $N_{c}$ the total number of cracks in the REV, the number of cracks of radius $r$ is equal to $\alpha_{c}(r)=N_{c} p_{c}(r)$. The length of the REV in the direction of the flow being equal to unity, the "volumetric frequency" of the cracks of radius $r$ is equal to $\alpha_{c}(r) \pi r^{2}$. As a result, the volume occupied by the cracks in the REV $\left(V_{c}\right)$ is defined as:

$$
V_{c}=\int_{r_{\min }^{c}}^{r_{\max }^{c}} \alpha_{c}(r) \pi r^{2} d r=\pi N_{c} \int_{r_{\min }^{c}}^{r_{\max }^{c}} p_{c}(r) r^{2} d r
$$

Four assumptions are made to get the equation of the Pore Size Distribution curve of the damaged porous rock sample.

1. The volume of a crack is entirely associated to damage growth, i.e. it is assumed that the creation and the growth of cracks create additional void space that does not stem from the coalescence of natural pores. This assumption is fundamental in most of the constitutive models based on Continuum Damage Mechanics [35, 36], and makes it possible to discriminate natural and damage-induced porosities. As a result, crack-induced porosity can be determined by using Equation 12 .

2. Cracks do not interact, i.e. cracks are not connected to each other. This assumption makes it possible to resort to a damage tensor of order two only to predict the anisotropy induced by cracking [34]. Moreover, assuming that cracks are not connected avoids all considerations about percolation thresholds in the permeability model $[2,6]$.

3. Cracks are connected to the natural pores. This assumption is commonly adopted in modeling frameworks dedicated to cracks permeability, even when the cracks are assumed not to be connected [68]. Moreover, the connectivity of cracks to the porous network is a necessary assumption, since the model is based on PSD curves, which are obtained 


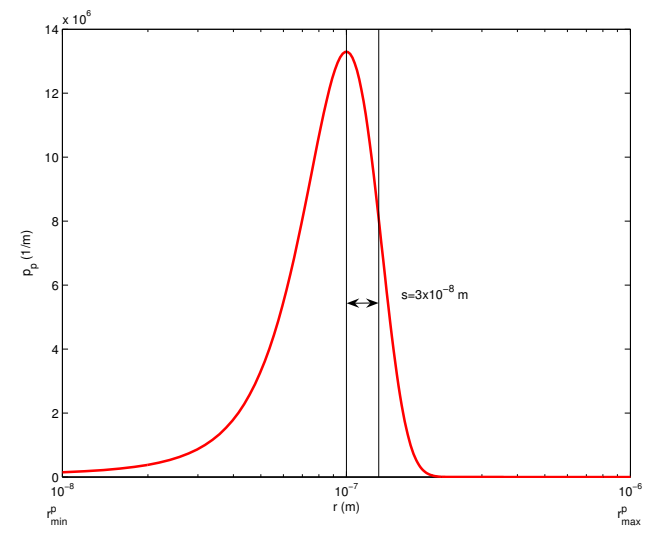

a.

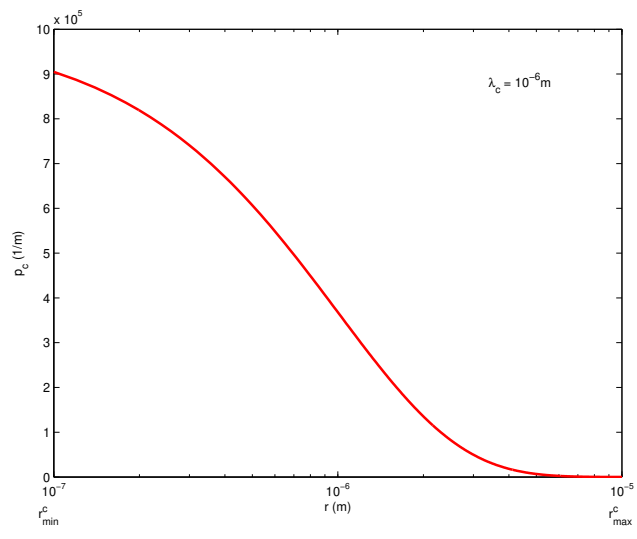

b.

Figure 3. Probability Density Functions of the radius distribution of a. the natural pores (Bell-shaped), b. the cracks (exponential).

from connected porosity measurements. As a result, damage growth always influences the intensity and the direction of fluid flow. The proposed model is unimodal in the sense of permeability (all pores are connected and form a unique porous network, characterized by a unique pressure head), but it is bimodal in the sense of porosity.

4. Natural pores and cracks are connected but do not intersect, so that there is no overlap between the volume occupied by the natural pores and the volume occupied by the cracks. The total volume of voids in the $\operatorname{REV}\left(V_{v}\right)$ can thus be obtained by adding the volume fraction of the natural pores to the volume fraction of the cracks:

$$
V_{v}=V_{p}+V_{c}
$$

According to the assumptions listed above, the number of pores (natural or damage-induced) of radius $r$ in the $\mathrm{REV}$ is equal to:

$$
\alpha(r)=\alpha_{p}(r)+\alpha_{c}(r)
$$

For a unit REV, with a length equal to unity in the direction of the flow, the "volume frequency" of the pores is equal to $\alpha(r) \pi r^{2}$, and the total porous space is expressed as:

$$
V_{v}=\int_{0}^{\infty} \alpha(r) \pi r^{2} d r=\int_{r_{\min }^{p}}^{r_{\max }^{p}} \alpha_{p}(r) \pi r^{2} d r+\int_{r_{\min }^{c}}^{r_{\max }^{c}} \alpha_{c}(r) \pi r^{2} d r
$$

Nine model parameters are required to characterize the PSD curve: the bounds limiting the range of values of the pore sizes $\left(r_{\min }^{p}\right.$ and $r_{\max }^{p}, r_{\min }^{c}$ and $\left.r_{\text {max }}^{c}\right)$, the number of natural pores $\left(N_{p}\right)$ and cracks $\left(N_{c}\right)$ in the REV, the expectancy $(m)$ and standard deviation $(s)$ of the pdf used for the natural pores size distribution, and the characteristic length of the cracks $\left(\lambda_{c}\right)$. We will see in the sequel that only four of these parameters are input data. The remaining are determined by means of equations relating the microstructure parameters to macroscopic characteristics of the REV. 


\subsection{Permeability}

The permeability model is based on two fundamental assumptions.

1. As explained in the preceding paragraph, the geometry of the porous network is represented by the Pore Size Distribution curve, which is updated with the state variables. The link with the PSD curve is based on a simple network geometry model [24]. The constitutive relationships result from isotropic flow equations.

2. The flow in the connected porous network constituted of natural pores and cracks is laminar, i.e. Hagen-Poiseuille flow model is adopted. This flow representation is a rough simplification of the physical processes at stake. In reality, a more refined flow model including turbulence is required to model the effects of fluid density and viscosity combined to the tortuosity of the porous network [19]. Although very simple, this assumption of laminar flow is adopted in many permeability models [24, 53, 55]. Moreover, refining the flow model without refining the geometric representation of the porous network (beyond the PSD curve) seems worthless. In usual problems of soil and rock mechanics, flow regimes are slow, so that fluid flow in tubes is indeed laminar. In other words, choosing a Hagen-Poiseuille flow model is consistent with assuming that the porous network is made of parallel cylinders.

The flow being assumed to be laminar, permeability can be defined by resorting to Darcy's law. Considering all the possible values that a tubular pore radius $(r)$ can take, and combining Hagen-Poiseuille flow equation to Darcy's law [24], hydraulic conductivity $\left(k_{w}\right)$ can be expressed as:

$$
k_{w}=\frac{\gamma}{8 \mu} \Phi \frac{1}{\int_{0}^{\infty} f(r) d r} \int_{0}^{\infty} f(r) r^{2} d r
$$

in which $\Phi$ is the total porosity of the medium (accounting for natural pores and cracks). The intrinsic permeability is defined by:

$$
k_{\text {int }}=\frac{\Phi}{8 \int_{0}^{\infty} f(r) d r} \int_{0}^{\infty} f(r) r^{2} d r
$$

In isothermal conditions $\left(\right.$ at $20^{\circ} \mathrm{C}$ ), the permeability (in $\mathrm{m} / \mathrm{s}$ ) can be obtained by multiplying the rock intrinsic permeability (in $\mathrm{m}^{2}$ ) by $10^{7}$. It is recalled that the length of the REV in the direction of the flow is assumed to be equal to unity, so that the "volume frequency" $f(r)$ is equal to the "area frequency":

$$
s f(r)=\alpha(r) \pi r^{2}=\left(N_{p} p_{p}(r)+N_{c} p_{c}(r)\right) \pi r^{2}
$$

\section{COMPUTATIONAL ALGORITHM}

\subsection{Updating the PSD Curve}

In the expression of hydraulic conductivity (Equation 16), two integrals need to be computed: $\int_{0}^{\infty} f(r) d r$ and $\int_{0}^{\infty} f(r) r^{2} d r$. In addition, porosity $(\Phi)$ needs to be updated. For a REV of unit length in the direction of the flow, the combination of Equations (15) and (18) gives:

$$
\int_{0}^{\infty} f(r) d r=V_{v}=\Phi \times V_{R E V}
$$


Using Equations (16) and (19):

$$
k_{w}=\frac{\gamma}{8 \mu} \frac{1}{V_{R E V}} \int_{0}^{\infty} f(r) r^{2} d r
$$

Using Equation (20), it appears that hydraulic conductivity needs to be updated with $V_{R E V}$ and $\int_{0}^{\infty} f(r) r^{2} d r$. Using the soil mechanics sign convention (compression positive), and assuming that the solid grains constituting the skeleton of the medium are incompressible:

$$
\frac{V_{R E V}-V_{R E V}^{0}}{V_{R E V}^{0}}=\delta: \epsilon=-\Delta \Phi=-\frac{V_{v}-V_{v}^{0}}{V_{R E V}^{0}}
$$

in which $V_{R E V}^{0}$ is the initial volume of the REV (it may be assumed to be equal to unity without loosing the generality of the model). Equation (21) shows that $V_{R E V}$ can be updated with total deformation.

The main steps to update $\int_{0}^{\infty} f(r) r^{2} d r$ with deformation and damage are explained in the sequel. According to Fig. 1, the increment of purely elastic strains at iteration $k$ is related to the stiffness tensor obtained at iteration $k-1$ by:

$$
d \boldsymbol{\epsilon}^{e l(k)}=\boldsymbol{D}\left(\boldsymbol{\Omega}^{(k-1)}\right)^{-1}: d \boldsymbol{\sigma}^{(k)}
$$

The increment of damage-induced deformation at iteration $k$ is obtained from the increment of total deformation (Equation (2) and Fig. 1):

$$
d \boldsymbol{\epsilon}^{d^{(k)}}=d \boldsymbol{\epsilon}^{e d^{(k)}}+d \boldsymbol{\epsilon}^{i d^{(k)}}=d \boldsymbol{\epsilon}^{(k)}-d \boldsymbol{\epsilon}^{e l(k)}
$$

where $d \boldsymbol{\epsilon}^{(k)}$ has been updated with damage in the current loading increment (this procedure is detailed in the next subsection). Using Equation (20), and recalling that the REV is equal to unity in the initial state (i.e. $V_{R E V}^{0}=1$ ), the volume occupied by all pores at iteration $k$ (natural pores and cracks) writes:

$$
V_{v}^{(k)}=-\boldsymbol{\delta}: \boldsymbol{\epsilon}^{(k)}+V_{v}^{0}
$$

The volume occupied by the cracks at iteration $\mathrm{k}$ corresponds to the porous volume created by damage-induced deformation. Assuming that there is no crack in the initial state (i.e. $V_{c}^{0}=0$ ) and that the REV is unity in the initial state (i.e. $V_{R E V}^{0}=1$ ), we have:

$$
V_{c}^{(k)}=-\delta: \epsilon^{d^{(k)}}
$$

According to the model assumption stated in Equation (13), the volume occupied by the natural pores at iteration $k$ is obtained by substracting the cracks volume from the total volume of pores:

$$
V_{p}^{(k)}=V_{v}^{(k)}-V_{c}^{(k)}
$$

Equations (22) to (26) provide a methodology to update the volume fractions $V_{p}$ and $V_{c}$ with deformation and damage. Equations (9) and (12) make it possible to update the model parameters used to define the PSD of the natural pores (respectively of the cracks) with $V_{p}$ (respectively $\left.V_{c}\right)$. Assuming that the lower and upper bounds of the pore sizes $\left(r_{\min }^{p}, r_{\max }^{p}\right.$, $r_{\min }^{c}$ and $\left.r_{\max }^{c}\right)$ are input parameters, the number of natural pores of radius $r\left(\alpha_{p}(r)\right)$ can 
be updated at iteration $k$ with $V_{p}^{(k)}$, and the number of cracks of radius $r\left(\alpha_{c}(r)\right)$ can be updated at iteration $k$ with $V_{c}^{(k)}$. According to Equations (14) and (18), updating $\alpha_{p}(r)$ and $\alpha_{c}(r)$ automatically updates the total "volumetric frequency" $f(r)$, which makes it possible to update $\int_{0}^{\infty} f(r) r^{2} d r$. This concludes the algorithm used to update permeability with damage and deformation.

As mentioned in Section 2, the PSD model depends on nine arguments, four of which have already been assumed to be input parameters $\left(r_{\min }^{p}, r_{\max }^{p}, r_{\min }^{c}\right.$ and $\left.r_{\max }^{c}\right)$. Equation (9) relates $V_{p}$ to three model parameters: $N_{p}, m$ and $s$. Following the assumptions of the model explained in section 2, any creation of new pores during a loading test is considered as induced by damage. In the same way, the disappearance of pores is associated to cracks closure. As a result, the number of cracks $\left(N_{c}\right)$ varies, but the number of natural pores $\left(N_{p}\right)$ can be considered as fixed in the computational algorithm. Additionally, it is assumed that the variations of the volume fraction $V_{p}$ mainly affects the mean radius of the natural pores $(m)$, and that the standard deviation $(s)$ can be considered as constant. With these assumptions, $s$ is a fixed parameter, and $m$ is a variable. If there is no crack in the initial state $\left(V_{c}^{0}=0\right.$, Equation (25)), the initial volume fraction of the natural pores can be determined from the initial void ratio $\left(e_{0}\right)$, which is easy to measure in the laboratory. Knowing that the REV is unity in the initial state, we have:

$$
V_{p}^{0}=V_{v}^{0}=\frac{e_{0}}{1+e_{0}}=\Phi_{0}
$$

Using Equation (9), we have:

$$
\Phi_{0}=\int_{r_{\min }^{p}}^{r_{\max }^{p}} \alpha_{p}^{0}(r) \pi r^{2} d r=\pi N_{p} \int_{r_{\min }^{p}}^{r_{\max }^{p}} p_{p}^{0}(r) r^{2} d r
$$

in which $p_{p}^{0}(r)$ is the probability density function assigned to the natural pores size distribution in the initial state:

$$
p_{p}^{0}(r)=\left\{\begin{array}{l}
\frac{1}{s \sqrt{2 \pi}} \exp \left(-\frac{\left(r-m_{0}\right)^{2}}{2 s^{2}}\right) \quad \text { if } \quad r_{\min }^{p} \leq r \leq r_{\max }^{p} \\
0 \text { otherwise }
\end{array}\right.
$$

where $m_{0}$ is the mean radius of the natural pores in the initial state. The number of natural pores in the REV $\left(N_{p}\right)$, the standard deviation $(s)$ and the initial mean radius of the natural pores $\left(m_{0}\right)$ are determined by combining Equations (7), (8) and (28). Then the mean radius of the natural pores is updated with $V_{p}$ according to Equation (9), by using the values of $N_{p}$ and $s$ obtained in the initialization computations. As explained in Section 2, the cracks characteristic length $\left(\lambda_{c}\right)$ is "adjusted to the bounds" $\left(r_{\min }^{c}\right.$ and $\left.r_{\max }^{c}\right)$ so that it is possible to define the mathematical expectancy of the pdf associated to the cracks size distribution over the interval $\left[r_{\min }^{c}, r_{\max }^{c}\right]$ (Equation (11)). As a result, $\lambda_{c}$ is not a variable. Damage growth is represented by an increase of the number of cracks in the REV. This means that $N_{c}$ is a variable. $N_{c}$ is updated with $V_{c}$ according to Equation (12). To summarize:

- The model requires four input parameters: $r_{\min }^{p}, r_{\max }^{p}, r_{\min }^{c}$ and $r_{\max }^{c}$.

- Three model parameters are computed in the initialization of the resolution algorithm: $N_{p}, s$ and $\lambda_{c}$. These initializations are based on mathematical conditions and on the knowledge of the initial void ratio. 
- Two model arguments are variables that need to be updated with deformation and damage: $m$ and $N_{c}$.

\subsection{Resolution Algorithm}

The algorithm explained below is designed for strain-controlled tests under drained conditions (null pore pressure).

\section{Initializations}

The number of natural pores in the REV $\left(N_{p}\right)$, the standard deviation of the pdf associated to the natural pores size distribution $(s)$ and the mean radius of the natural pores in the initial state $\left(m_{0}\right)$ are computed by solving the following system of equations:

$$
\left\{\begin{array}{l}
V_{p}^{0}=\Phi_{0}=\pi N_{p} \int_{r_{\min }^{p}}^{r_{\max }^{p}} p_{p}^{0}(r) r^{2} d r \\
m_{0} \approx \int_{r_{\min }^{p}}^{r_{\max }^{p}} p_{p}^{0}(r) r d r \\
1 \approx \int_{r_{\min }^{p}}^{r_{\max }^{p}} p_{p}^{0}(r) d r
\end{array}\right.
$$

in which the initial probability density function $p_{p}^{0}(r)$ is defined in Equation (29).

The cracks characteristic length is "adjusted to the bounds" $r_{\min }^{c}$ and $r_{\text {max }}^{c}$ :

$$
\lambda_{c} \approx \int_{r_{\min }^{c}}^{r_{\max }^{c}} p_{c}(r) r d r
$$

in which the probability density function $p_{c}(r)$ is defined in Equation (10).

\section{Iterative Resolution Process}

1. From $d \boldsymbol{\epsilon}$ to $(d \boldsymbol{\Omega}, d \boldsymbol{\sigma})$ :

For a strain-controlled test, the increment of strain applied at iteration $k$ is known. A trial increment of stress is computed, assuming that the material remains elastic during the loading iteration:

$$
d \boldsymbol{\sigma}^{(k, *)}=\boldsymbol{D}\left(\boldsymbol{\Omega}^{(k-1)}\right): d \boldsymbol{\epsilon}^{(k)}
$$

Total strains are updated with the known incremental strains:

$$
\boldsymbol{\epsilon}^{(k)}=\boldsymbol{\epsilon}^{(k-1)}+d \boldsymbol{\epsilon}^{(k)}
$$

The sign of the damage evolution function is checked:

$$
\left\{\begin{array}{l}
\text { if } f_{d}\left(\boldsymbol{\Omega}^{(k-1)}, \boldsymbol{\epsilon}^{+(k)}\right)<0: \\
d \boldsymbol{\Omega}^{(k)}=0, \quad d \boldsymbol{\sigma}^{(k)}=d \boldsymbol{\sigma}^{(k, *)} \\
\text { if } f_{d}\left(\boldsymbol{\Omega}^{(k-1)}, \boldsymbol{\epsilon}^{+(k)}\right) \geq 0: \\
d \boldsymbol{\Omega}^{(\boldsymbol{k})}>0, \quad d \boldsymbol{\sigma}^{(k)} \neq d \boldsymbol{\sigma}^{(k, *)}
\end{array}\right.
$$


If damage occurs during the iteration, $d \boldsymbol{\Omega}^{(k)}$ is computed by using the damage criterion (Equation (5)) and an associated flow rule. Using Equation (3):

$$
\begin{gathered}
\boldsymbol{\sigma}=\boldsymbol{D}(\boldsymbol{\Omega}): \boldsymbol{\epsilon}-\boldsymbol{D}(\boldsymbol{\Omega}): \boldsymbol{\epsilon}^{i d} \\
d \boldsymbol{\sigma}=\boldsymbol{D}(\boldsymbol{\Omega}): d \boldsymbol{\epsilon}+\left(\frac{\partial \boldsymbol{D}(\boldsymbol{\Omega})}{\partial \boldsymbol{\Omega}}: \boldsymbol{\epsilon}\right): d \boldsymbol{\Omega}-d\left(\boldsymbol{D}(\boldsymbol{\Omega}): \boldsymbol{\epsilon}^{i d}\right)
\end{gathered}
$$

By definition of the damage-induced residual stress and residual strains (Equation 4):

$$
\begin{aligned}
& d \boldsymbol{\sigma}=\boldsymbol{D}(\boldsymbol{\Omega}): d \boldsymbol{\epsilon}+\left(\frac{\partial \boldsymbol{D}(\boldsymbol{\Omega})}{\partial \boldsymbol{\Omega}}: \boldsymbol{\epsilon}\right): d \boldsymbol{\Omega}-d \boldsymbol{\sigma}_{\boldsymbol{R}} \\
& d \boldsymbol{\sigma}=\boldsymbol{D}(\boldsymbol{\Omega}): d \boldsymbol{\epsilon}+\left(\frac{\partial \boldsymbol{D}(\boldsymbol{\Omega})}{\partial \boldsymbol{\Omega}}: \boldsymbol{\epsilon}\right): d \boldsymbol{\Omega}+g d \boldsymbol{\Omega}
\end{aligned}
$$

If damage occurs at iteration $k$, the stress increment is updated with the imposed strain increment as follows:

$$
d \boldsymbol{\sigma}^{(k)}=\boldsymbol{D}\left(\boldsymbol{\Omega}^{(k-1)}\right): d \boldsymbol{\epsilon}^{(k)}+\left(\frac{\partial \boldsymbol{D}\left(\boldsymbol{\Omega}^{(k-1)}\right)}{\partial \boldsymbol{\Omega}}: \boldsymbol{\epsilon}^{(k-1)}\right): d \boldsymbol{\Omega}^{(k)}-g d \boldsymbol{\Omega}^{(k)}
$$

2. From $(d \boldsymbol{\Omega}, d \boldsymbol{\sigma})$ to $\left(V_{c}, V_{p}\right)$ :

After updating total strains, it is possible to get the volume of pores in the REV at iteration $k$ (Equations (24) and (27)):

$$
\boldsymbol{\epsilon}^{(k)}=\boldsymbol{\epsilon}^{(k-1)}+d \boldsymbol{\epsilon}^{(k)}, \quad V_{v}^{(k)}=-\operatorname{Tr}\left(\boldsymbol{\epsilon}^{(k)}\right)+\Phi_{0}
$$

For any iteration, in loading or unloading conditions:

$$
d \boldsymbol{\epsilon}^{e l(k)}=\boldsymbol{D}\left(\boldsymbol{\Omega}^{(k-1)}\right)^{-1}: d \boldsymbol{\sigma}^{(k)}
$$

The combination of Equations (40) and (41) gives:

$$
d \boldsymbol{\epsilon}^{d^{(k)}}=d \boldsymbol{\epsilon}^{(k)}-d \boldsymbol{\epsilon}^{e l(k)}, \quad \boldsymbol{\epsilon}^{d^{(k)}}=\boldsymbol{\epsilon}^{d^{(k-1)}}+d \boldsymbol{\epsilon}^{d^{(k)}}
$$

from which it is possible to update the volume fractions of the cracks and of the natural pores (Equations (25) and (26)):

$$
V_{c}^{(k)}=-\operatorname{Tr}\left(\epsilon^{d^{(k)}}\right), \quad V_{p}^{(k)}=V_{v}^{(k)}-V_{c}^{(k)}
$$

3. From $\left(V_{c}, V_{p}\right)$ to $k_{w}$ :

The mean value of the radius of the natural pores at iteration $k\left(m^{(k)}\right)$ is updated with the volumetric fraction of the natural pores $\left(V_{p}{ }^{(k)}\right)$ :

$$
V_{p}^{(k)}=\pi N_{p} \int_{r_{\min }^{p}}^{r_{\max }^{p}}\left(\frac{1}{s \sqrt{2 \pi}} \exp \left(-\frac{\left(r-m^{(k)}\right)^{2}}{2 s^{2}}\right)\right) r^{2} d r
$$

in which $N_{p}$ and $s$ are fixed parameters that have been determined in the initialization of the computational algorithm (Equation 30). 
The number of cracks in the REV at iteration $k\left(N_{c}^{(k)}\right)$ is updated with the volumetric fraction of the cracks $\left(V_{c}^{(k)}\right)$ :

$$
V_{c}^{(k)}=\pi N_{c}^{(k)} \int_{r_{\min }^{c}}^{r_{\max }^{c}} \frac{1}{\lambda_{c}} \exp \left(-\frac{r}{\lambda_{c}}\right) r^{2} d r
$$

in which $\lambda_{c}$ is a fixed parameter that has been determined in the initialization of the computational algorithm (Equation 31).

Once $m$ and $N_{c}$ have been updated, it is possible to update the number of natural pores of size $r$ at iteration $k\left(\alpha_{p}^{(k)}(r)\right)$ and the number of cracks of size $r$ at iteration $k$ $\left(\alpha_{c}^{(k)}(r)\right)$. Then the update of the "volumetric frequency" at iteration $k$ is straightforward (Equations 14 and 18):

$$
f^{(k)}(r)=\left(\alpha_{p}^{(k)}(r)+\alpha_{c}^{(k)}(r)\right) \pi r^{2}
$$

At iteration $k$, hydraulic conductivity is updated by using Equation (16):

$$
k_{w}{ }^{(k)}=\frac{\gamma}{8 \mu}\left(\Phi_{0}+\operatorname{Tr}\left(-\boldsymbol{\epsilon}^{(k)}\right)\right) \frac{1}{\int_{0}^{\infty} f^{(k)}(r) d r} \int_{0}^{\infty} f^{(k)}(r) r^{2} d r
$$

in which $\Phi_{0}$ is the initial porosity of the REV (Equation (27)).

\section{DRAINED TRIAXIAL COMPRESSION TEST}

\subsection{Numerical Model}

The algorithm presented in Section 3 is used to evaluate permeability in an unconfined granite sample subjected to uniaxial compressive loading (applied in direction 1). It is assumed that the damage tensor remains parallel to the principal stress directions. A drained triaxial compression test is simulated, by increasing $\epsilon_{1}$ by increments while maintaining $\sigma_{2}$ and $\sigma_{3}$ equal to zero. Tensile strains develop in lateral directions only, so that the axial component of damage remains equal to zero (i.e. $\Omega_{1}=0$ ). When cracking occurs, damage grows equally in directions 2 and 3 because of the symmetry of the considered problem. $\sigma_{1}, \epsilon_{2}$ and $\epsilon_{3}$ are updated iteratively, along with $\Omega_{2}$ and $\Omega_{3}$, as explained in Section 3. The material under study is a granite for which experimental results on triaxial compression tests have already been published [30]. The mechanical damage model presented in Section 2 has proved to reproduce well the semi-brittle behavior of this granite $[4,28]$. The main material parameters are summarized in Table I. The mechanical parameters $\left(E_{0}, \nu_{0}, g, C_{0}, C_{1}\right)$ are taken equal to the ones that are calibrated in $[4,28]$. The initial void ratio $\left(e_{0}\right)$ is taken equal to the void ratio measured on Vienne granite [30], which is the rock studied in the calibration presented in $[4,28]$. The minimum and maximum radii of the granite natural pores $\left(r_{\min }^{p}\right.$ and $\left.r_{\max }^{p}\right)$ are chosen so that the mean of $r_{p}$ can be expected to be of the order of $0.1 \mu \mathrm{m}$, as stated in [3]. The orders of magnitude for the minimum and maximum radii of the cracks $\left(r_{\min }^{c}\right.$ and $\left.r_{\max }^{c}\right)$ are chosen according to Maleki [40], who also worked on damage in rock materials.

\subsection{Mechanical Response}

The plot showing the variations of the deviatoric stress $q=\sigma_{1}-\sigma_{3}=\sigma_{1}$ is typical of a brittle material (Fig. 4.a). Even after damage initiation (at around $\epsilon_{1}=0.001$ ), the stress/strain 
Table I. Main Material Parameters Used to Simulate a Drained Triaxial Compression Test on Granite.

\begin{tabular}{cccccc}
\hline$E_{0}(\mathrm{~Pa})$ & $\nu_{0}(-)$ & $\mathrm{g}(\mathrm{Pa})$ & $C_{0}(\mathrm{~Pa})$ & $C_{1}(\mathrm{~Pa})$ & $e_{0}(-)$ \\
$8.01 e 10$ & 0.28 & $-3.3 e 8$ & $1.1 e 5$ & $2.2 e 6$ & 0.008 \\
\hline $\begin{array}{c}r_{\min }^{p}(\mu m) \\
0.01\end{array}$ & $r_{\max }^{p}(\mu m)$ & $r_{\min }^{c}(\mu m)$ & $r_{\max }^{c}(\mu m)$ \\
& 1 & 0.1 & 10 & & \\
\hline
\end{tabular}

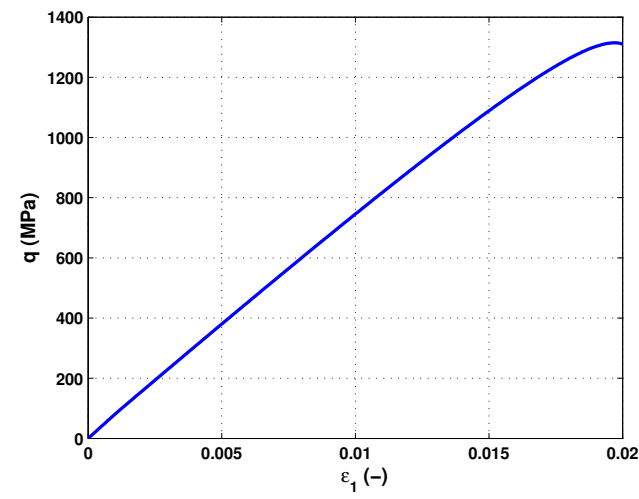

a.

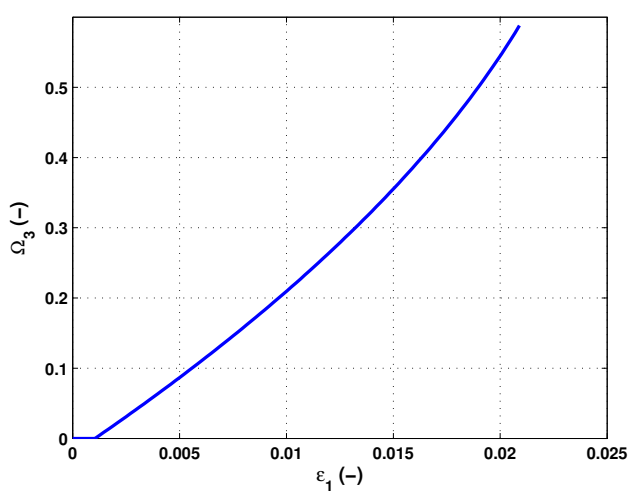

b.

Figure 4. Mechanical Response of the Granite Sample during an Unconfined Triaxial Compression Test. a. Deviatoric Stress versus Axial Strain. b. Lateral Damage versus Axial Strain.

curve is almost a straight line. The stiffness decrease is more evident for axial deformation above $1.3 \%$, when lateral damage $\left(\Omega_{2}=\Omega_{3}\right)$ gets over $30 \%$. The peak of stress is reached when $\epsilon_{1}=1.8 \%$, with a lateral damage of about $53 \%$ (Fig. 4.b). The quasi-absence of strain softening is typical of an almost perfectly brittle material, like granite. The mechanical response illustrated in Fig. 4 is in conformity with the reference results published in [4, 28].

\subsection{Impact of Deformation and Damage on Porosity and Permeability}

It appears from Fig. 5.a that the mean natural pore radius $(m)$ decreases when compression (controlled by the driving strain $\epsilon_{1}$ ) increases. This observation is consistent with the measurements reported by Romero [49], who noticed that under a given compressive load, larger pores reduce prior to the smaller pores. As a result, for a fixed total number of pores in the REV $\left(N_{p}\right)$, the proportion of larger pores decreases while the proportion of smaller pores increases. Consequently, the mean natural pore size is "shifted to the left" on the PSD curve, i.e. the average pore radius size decreases. Overall, the size reduction of the larger pores results in a decrease of the volume fraction of the natural pores $\left(V_{p}\right)$ in the REV. Since $V_{p}$ variations represent elastic volumetric strains (see Equations (42), (43)), the expected decrease 


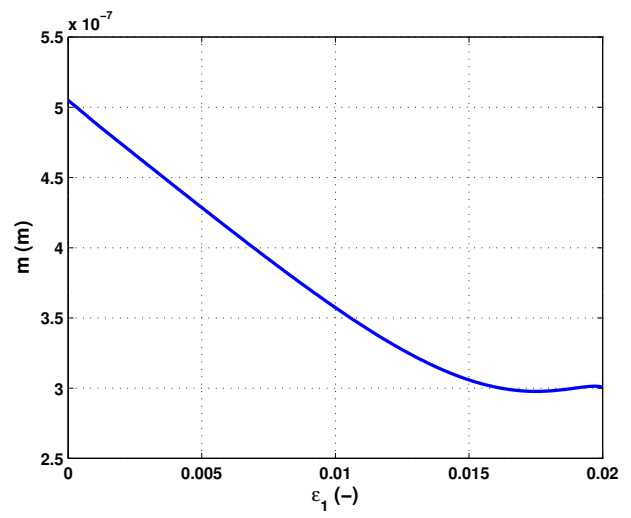

a.

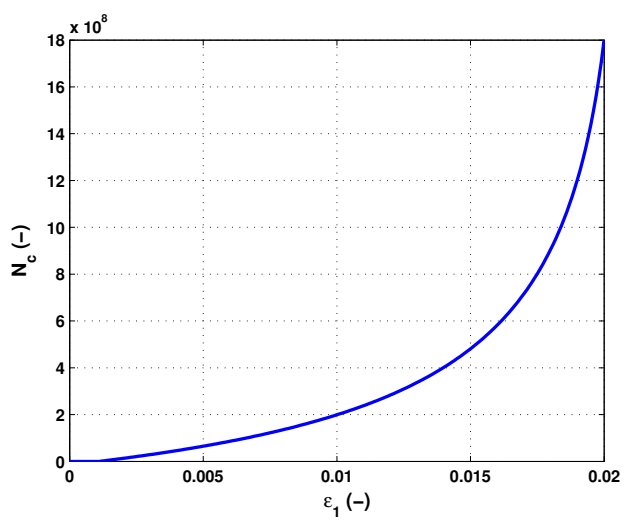

b.

Figure 5. Evolution of the Parameters of the Area Frequencies During the Triaxial Compression Test. a. Average Radius Size of the Natural Pores. b. Number of Cracks.

of the natural pores volume is expected to be of the order of 0.001 times the Representative Elementary Volume. The results obtained meet these theoretical expectations (Fig. 6.a). After the peak of stress, softening starts to occur (Fig. 4.a), so that the REV mean stress decreases, which results in an increase of the natural pore size (compression is released). As a result, the average radius size of the natural pores starts to increase after the peak of stress, reached at $\epsilon_{1}=1.8 \%$ (Fig. 6.a).

As the compressive deviatoric load increases, not only natural pores are compressed, but also tensile cracks open in the direction parallel to higher principal stress direction (direction 1 in this example, with the soil mechanics sign convention). The characteristic cracks length $\left(\lambda_{c}\right)$ is a fixed parameter of the model, computed in the initialization of the algorithm (Equation (31)). The increase of the cracks volume fraction induced by damage growth is modeled by an increase of the number of open cracks $\left(N_{c}\right)$, as illustrated by Fig. 5.b. In the proposed modeling framework, the number of open cracks increases while the size (or volume) of each individual crack remains constant. As a result, the volume fraction of the cracks in the REV $\left(V_{c}\right)$ is expected to increase with axial deformation $\left(\epsilon_{1}\right)$. Fig. 6.a. shows that the theoretical expectations are satisfied. The order of magnitude of the variations of $V_{c}$ are about ten times higher than the order of magnitude of the variations of $V_{p}$, so that the evolution of the sample volume $\left(V_{R E V}\right)$ is mainly controlled by the evolution of the cracks volume $\left(V_{c}\right)$, as shown in Fig. 6. a \& b.

With a lateral damage peaking at $58 \%$, hydraulic conductivity increases by more than two orders of magnitude, as can be seen in Fig. 7.b. Before damage initiates, for an axial deformation less than 0.001 , hydraulic conductivity decreases slightly, which is the consequence of the elastic compression of the larger natural pores, as explained in the previous paragraph (Fig. 7.a). 


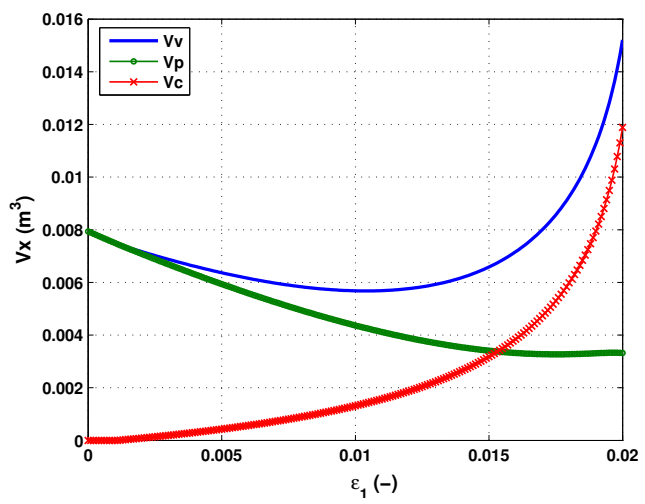

a.

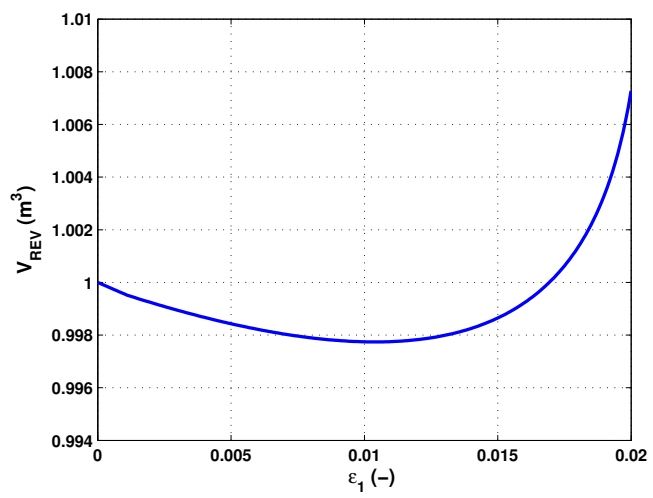

b.

Figure 6. Volume Evolution During the Triaxial Compression Test. a. Total Porous Volume $\left(V_{v}\right)$, Natural Porous Volume $\left(V_{p}\right)$ and Cracks Volume $\left(V_{c}\right)$. b. Representative Elementary Volume.

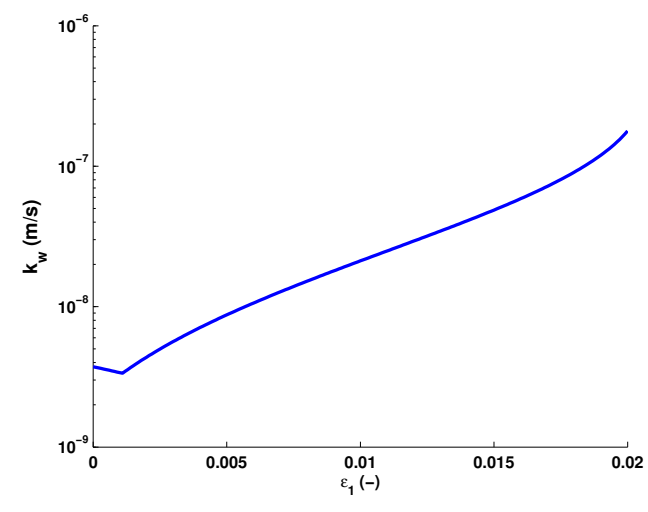

a.

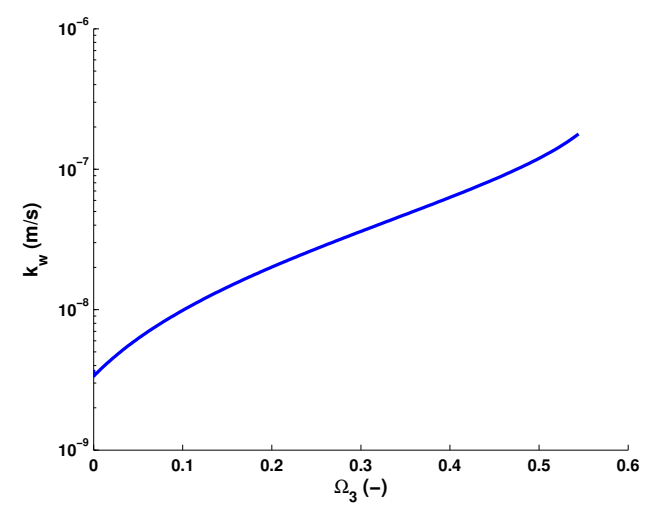

b.

Figure 7. Evolution of Hydraulic Conductivity with: a. Axial Strain. b. Lateral Damage.

\section{PERFORMANCE OF THE MODEL TO REPRESENT THE INFLUENCE OF THE CONFINING PRESSURE}

\subsection{Calibration of the Model}

The model is now calibrated to reproduce the permeability change measured during a triaxial compression test performed on Lac du Bonnet Granite. The test is described in [57]. The experimental results have been used to calibrate Shao et al.'s damaged permeability model [55]. The confining pressure $\left(p_{c}\right)$ applied in the reference test amounts to $10 \mathrm{MPa}$. The confining phase is simulated by applying an isotropic strain, calibrated to reach a mean stress equal to the confining pressure. The compression phase is simulated by increasing $\epsilon_{1}$ by increments, while maintaining $\sigma_{2}=\sigma_{3}=p_{c}$. The undamaged Young's modulus and Poisson's coefficient 
are chosen according to Shao et al.'s calibration. Shao et al. consider that cracks are pennyshaped. In the present model, cracks are assumed to be cylinders. The radii of these cylinders are equal to cracks apertures $\left(a_{0}\right)$ in Shao et al.'s model: $a_{0}=\chi \times r_{0}$ in which $\chi$ is a dilatance parameter (with $\chi=0.005$ for granite rock), and $r_{0}$ is the initial radius of the penny-shaped cracks $\left(r_{0}=3 \mathrm{~mm}\right.$ according to Shao et al.). Cracks coalesce when their radius is equal to a critical value: $r_{c}=3 \times r_{0}=9 \mathrm{~mm}$, which corresponds to an aperture of $a_{c}=4.5 \cdot 10^{-5} \mathrm{~m}$. As a result, the simulations presented in this paper are run with $r_{c}^{\max }=a_{c}=4.5 \cdot 10^{-5} \mathrm{~m}$. Moreover $r_{c}^{\min }$ is chosen of the same order of magnitude as $a_{0}=\chi \times r_{0}: r_{c}^{\min }=\chi r_{0} / 3=5 \cdot 10^{-6} \mathrm{~m}$.

To reproduce the initial permeability state of Lac du Bonnet granite, Shao et al. propose a single porosity model, in which the rock is considered as a fractured solid. The initial total porosity estimated by Shao et al. is of the order of $10^{-4}$ and the initial permeability measured in the triaxial compression test is of the order of $10^{-20} \mathrm{~m}^{2}$. According to the model proposed in this paper, this would set the initial connected porosity to a very low value (of the order of $10^{-9}$ ). Setting a very low initial porosity allows very little pores compression. This does not matter in Shao et al.' model, which does not account for the influence of the strain tensor and natural pores deformation on permeability. However, the model proposed in this study is based on a double porosity framework, which requires the definition of a realistic undamaged connected porosity. As a result, like in the preceding numerical study (Section 4), the initial void ratio is taken equal to the one measured in [30] for Vienne granite, and the bounds for the natural pores size $\left(r_{p}^{\min }\right.$ and $\left.r_{p}^{\max }\right)$ are chosen according to the recommendations of Alves et al. [3]. This modeling choice does not allow the reproduction of the initial permeability state measured before the triaxial compression test. The objective of the model calibration presented in this section is to assess the performance of the model to predict the increase of permeability under a given confining pressure. The main material parameters used for the corresponding simulations are summarized in Table II.

In the absence of reference data on the resistance to crack closure in Shao et al.'s article, $g$ is taken equal to $-3.3 \cdot 10^{8} \mathrm{~Pa}$, which is typical of granite, as explained in Section 4. The initial damage threshold $\left(C_{0}\right)$ is calibrated with the experimental data reported in [55], in order to trigger damage when permeability starts to increase with deviatoric stress (which corresponds to cracks opening). The hardening parameter $\left(C_{1}\right)$ is calibrated in order to generate an increase of initial permeability of the same order of magnitude as in the reference triaxial test described in [57]. In the reference test, hydraulic conductivity increases by three orders of magnitude: $k_{w} / k_{0} \simeq 1000$, where $k_{0}$ is the rock hydraulic conductivity in the initial damage state (damaged in Shao et al.'s model, undamaged in the proposed model). Predictions on damaged hydraulic conductivity are compared to Shao et al.'s model in Fig. 8.a. Both models have been calibrated with the same experimental data, and both models perform well to represent the permeability increase due to cracking. It has to be noted that the reference data found in [57] and [55] deals with axial permeability measured during triaxial compression test. Shao et al. consider that the damaged permeability is a tensor, whereas the model proposed in this paper is based on a concept of $1 \mathrm{D}$ flow in a bundle of parallel cylinders. However, during a triaxial compression test, cracks open in planes that are normal to the lateral directions, so that it makes sense to represent the cracks volume fraction by cylinders that are parallel to the loading axis. In the sequel, the "isotropic" permeability predicted by the model proposed in this paper is thus 
Table II. Main Material Parameters Used to Study the Influence of the Confining Pressure.

\begin{tabular}{cccccc}
\hline$E_{0}(\mathrm{~Pa})$ & $\nu_{0}(-)$ & $\mathrm{g}(\mathrm{Pa})$ & $C_{0}(\mathrm{~Pa})$ & $C_{1}(\mathrm{~Pa})$ & $e_{0}(-)$ \\
$6.8 e 10$ & 0.21 & $-3.3 e 8$ & $1.8 e 5$ & $8 e 5$ & 0.008 \\
\hline $\begin{array}{c}r_{\min }^{p}(\mu m) \\
0.01\end{array}$ & $r_{\max }^{p}(\mu m)$ & $r_{\min }^{c}(\mu m)$ & $r_{\max }^{c}(\mu m)$ & & \\
\hline
\end{tabular}

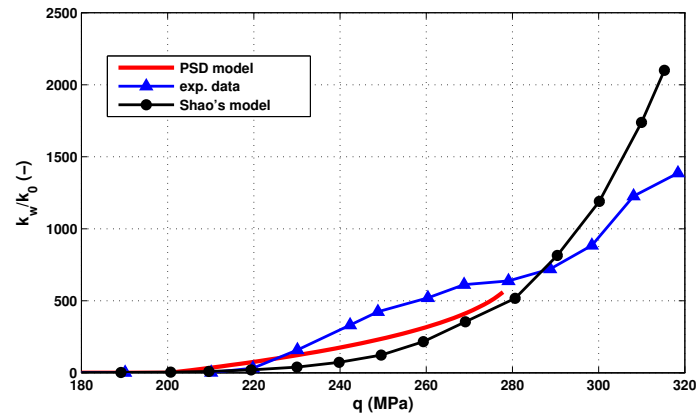

a.

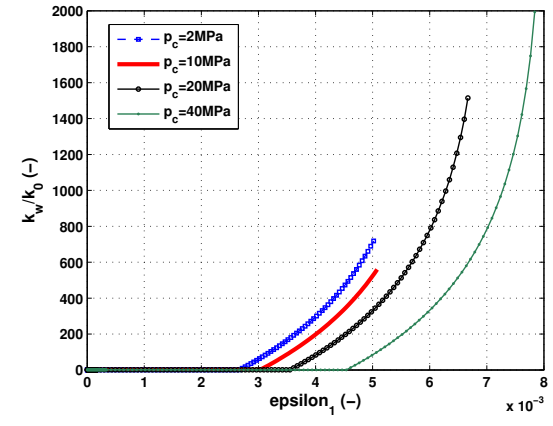

b.

Figure 8. a. Comparison of the Proposed Model with Shao et al.'s Model (the model is calibrated with experimental data and the simulation results are compared to Shao et al.'s numerical computations). b. Effect of the Confining Pressure on the Evolution of Hydraulic Conductivity (the case $p_{c}=10 \mathrm{MPa}$ is set as reference).

compared to Shao et al.'s damaged axial permeability.

\subsection{Parametric Study: Effect of the Confining Pressure on Permeability Evolution}

After calibration, the model is used to simulate triaxial compression tests with other confining pressures. As illustrated in Fig. 8.b, the permeability jump occurs at higher deformation as the confining pressure increases. Indeed, for a given axial compression strain, the higher the confining pressure, the lower lateral tensile strains, and the lower lateral damage (Fig. 9.b). As a result, the same increase of hydraulic conductivity is reached at a lower axial strain for lower confining pressures. As expected, the axial strain corresponding to the peak of deviatoric stress is higher when the confining pressure is higher (Fig. 9.a).

Because the compression applied at low confining pressure is smaller than at high confining pressure, the larger natural pores get more squeezed during the triaxial tests with higher confining pressure. As a result, the decrease of the average natural pore radius size $(m)$ is more significant for $p_{c}=20 \mathrm{MPa}$ and $p_{c}=40 \mathrm{MPa}$ than for $p_{c}=2 \mathrm{MPa}$ and $p_{c}=10 \mathrm{MPa}$, as illustrated in Fig. 10.a. Moreover, a clear softening is observed at higher confining pressures, which results in a release of the sample mean stress, and thus, in a relaxation of the compression 


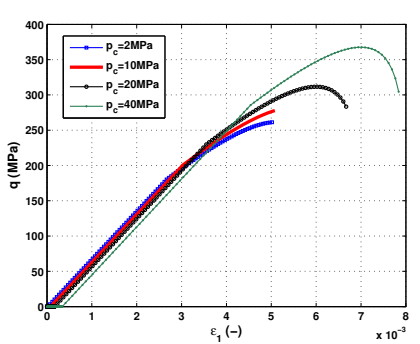

a.

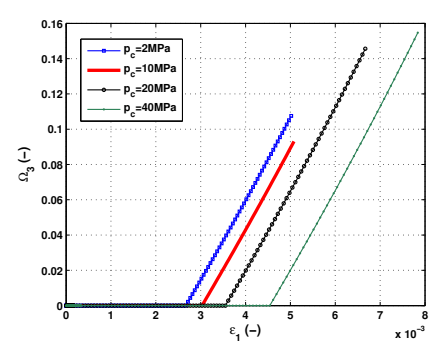

b.

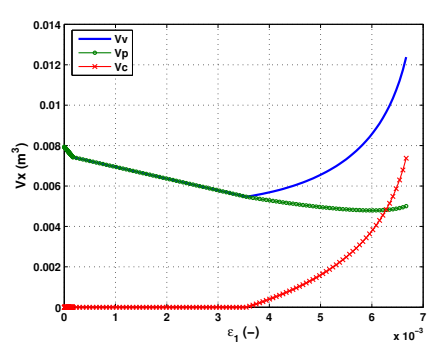

c.

Figure 9. Influence of the Confining Pressure on the Peak of Deviatoric Stress (a.) and on Damage Evolution (b.). c. Porous Volumes Evolution for $p_{c}=20 \mathrm{MPa}$.

applied to the natural pores. Consequently, $m$ increases after reaching a minimum at the peak of deviatoric stress (see $p_{c}=20 \mathrm{MPa}$ and $p_{c}=40 \mathrm{MPa}$ in 10.a). The number of open cracks increases with axial strains in the four tests (Fig. 10.b). Damage initiation is delayed as the confining pressure is increased. The observed delay is the same on lateral damage (Fig. 9.b) and on the number of cracks (Fig. 10.b), which shows the consistency of the model.

Before the occurrence of damage, the porous volume decreases due to the elastic compression of the natural pores, and after damage initiation, the porous volume is mainly controlled by the increase of the cracks density (Fig. 9.c). The sample volume decreases faster in the elastic confining phase than in the elastic compression phase, which explains the bilinear form of the plot representing the evolution of the Representative Elementary Volume with axial deformation in Fig. 11.a. Once damage is initiated, the cracks volume increase quickly dominates the natural pores volume decrease, and the volume of the REV grows according to the cracks volume increase (Fig. 11.a and 9.c).

The four triaxial compression tests presented in this section are simulated till the peak of deviatoric stress, which corresponds to the cracks coalescence in each of the four tests. That is why the increase of hydraulic conductivity is similar in the four cases, as illustrated in Fig. 11.b. As could be expected, the decrease of permeability associated to the elastic compression of the natural pores spreads over a larger interval of axial strains as the confining pressure is increased.

\section{CONCLUSION}

A new permeability model is proposed for damaged porous rocks. Natural pores and cracks are represented as parallel cylinders with various radii. In a damaged rock, the Pore Size Distribution (PSD) curve shows two modes. The size distribution of the natural pores is chosen to be a log-normal distribution, and the cracks size distribution is modeled by an exponential law. Both probability density functions (pdf) are defined on an acceptable range of values of pore sizes. Permeability is related to the pore size distributions using Darcy's law and Hagen- 


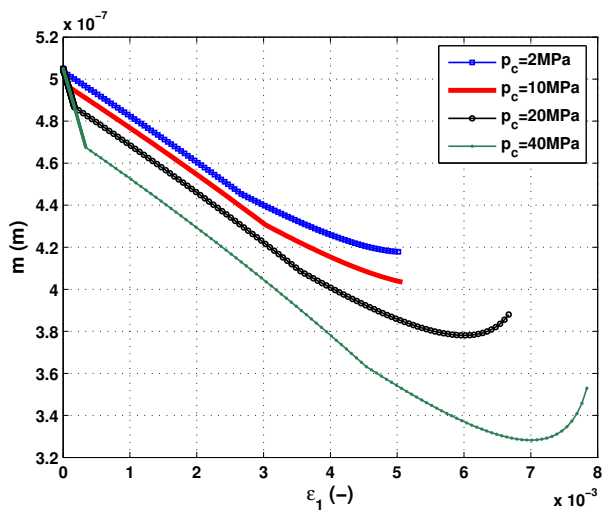

a.

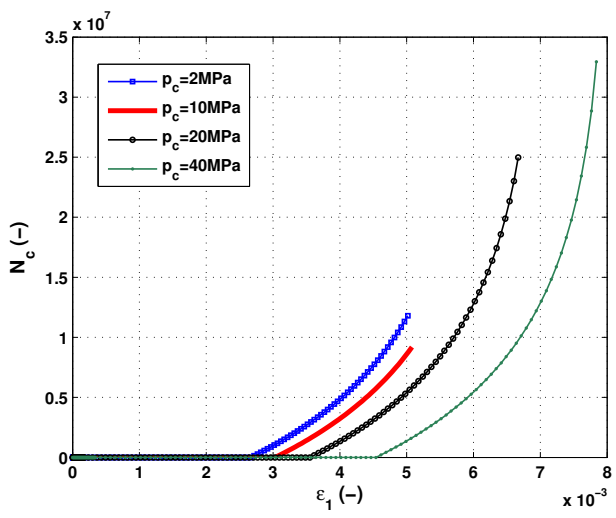

b.

Figure 10. Influence of the Confining Pressure on: a. The Average Size of Natural Pores. b. The Number of Cracks in the REV.

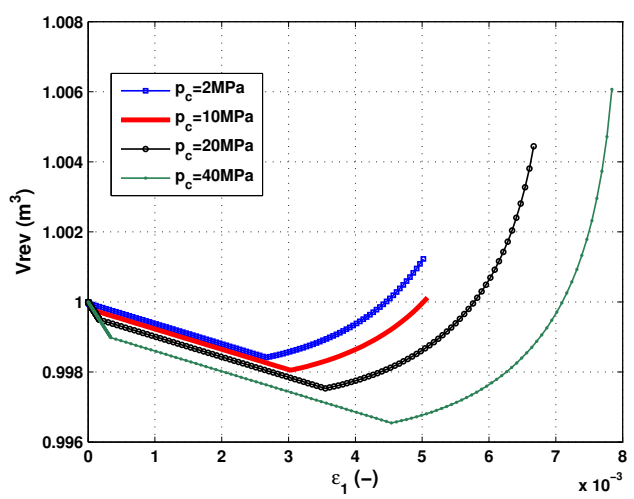

a.

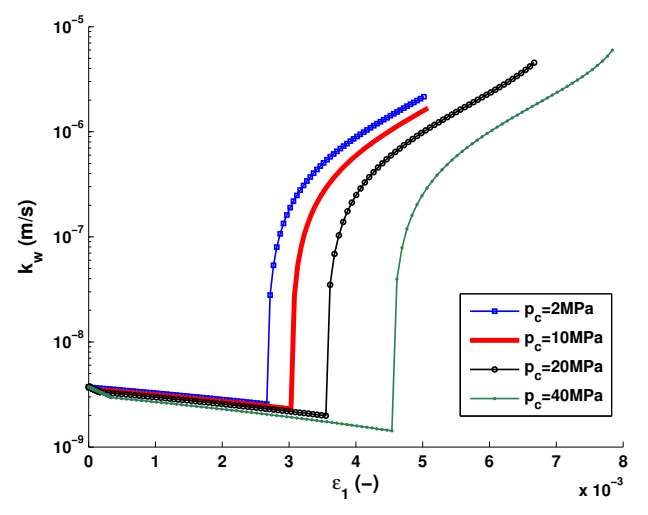

b.

Figure 11. Influence of the Confining Pressure on the REV Size (a.) and Hydraulic Conductivity (b.)

Poiseuille equation. The challenge consists in updating the size distribution of pores with both deformation and damage. The work is two-fold: 1 . relate the volume fraction of natural pores $\left(V_{p}\right)$ and the volume fraction of cracks $\left(V_{c}\right)$ to the strain and damage tensors, 2. update the parameters of the probability density function characterizing the size distribution of natural pores (respectively cracks) with $V_{p}$ (respectively $V_{c}$ ). The minimum and maximum values allowed for the pores and cracks radii $\left(r_{\min }^{p}, r_{\max }^{p}\right.$ and $\left.r_{\min }^{c}, r_{\max }^{c}\right)$ are input parameters. Fixing the bounds of the definition domain of the pdf associated to the natural pores size distribution (with $r_{\min }^{p}$ and $r_{\max }^{p}$ ) provides two mathematical conditions that have to be satisfied by the standard deviation $(s)$ and the mean natural pore size $(m)$. The initial volume fraction of the natural pores is determined by the initial void ratio measured in the rock in the reference state (before loading, and supposedly in the absence of damage). A system of three independent equations is obtained, which allows the determination of the initial number of natural pores 
$\left(N_{p}^{0}\right)$ in the Representative Elementary Volume (REV), the initial standard deviation of the pdf associated to the natural pores size distribution $\left(s^{0}\right)$, and the initial average radius of the natural pores $\left(m_{0}\right)$. The number of natural pores $\left(N_{p}\right)$ and the standard deviation $(s)$ are assumed to be fixed model parameters $\left(N_{p}=N_{p}^{0}, s=s^{0}\right)$, and only the average radius of the natural pores $(m)$ is updated with the natural pores volume fraction $\left(V_{p}\right)$ when deformation and damage occur. The characteristic crack length $\left(\lambda_{c}\right)$ is "adjusted to the bounds" $r_{\min }^{c}$ and $r_{\text {max }}^{c}$, and is considered as a fixed model parameter. In the initial state, it is assumed that the REV contains no open crack. When damage occurs, the number of cracks in the REV $\left(N_{c}\right)$ is updated with the cracks volume fraction $\left(V_{c}\right)$. The pore volume frequencies depend on the pdfs associated with the pores size distributions, which are updated at each iteration with $V_{p}$ and $V_{c}$, and thus, with deformation and damage.

The permeability model presented in this article is easy to plug into any damage model for which Helmholtz free energy and the damage criterion are known. The approach can also be applied to model ore forming mechanisms, in which thermal expansion and chemical dissolution play a critical role in the evolution of porosity and permeability. A damage variable is not mandatory, as long as the physical processes at stake are accounted for with the appropriate thermodynamic state variables. The key assumptions are the decomposition of the total deformation tensor and the relationship between strain components and Pore Size Distribution parameters. In this paper, the permeability model is coupled to a mechanical damage model representing the evolution of mode I cracks with tensile strains. This mechanical model has already been calibrated and validated for granite. The proposed framework, coupling PSD curves evolution and permeability variations with state variables updates, has been implemented in a numerical code. The algorithm is based on an explicit scheme, and is primarily designed to simulate strain-controlled tests. Drained triaxial compression tests are simulated on granite samples, using the mechanical damage parameters calibrated in previous works. The numerical model is able to predict the decrease of the average size of the natural pores as the sample is compressed, which is associated to the size reduction of the larger pores of the undamaged matrix. As long as the sample remains elastic, the decrease of the natural pores volume fraction $V_{p}$ results in a slight decrease of permeability. When damage occurs, it is verified that the number of cracks increases up to the stress peak, and that correspondingly, the cracks volume fraction $V_{c}$ increases. As soon as damage occurs, the permeability decrease induced by the shrinkage of the larger natural pores becomes negligible compared to the permeability increase induced by cracking. The proposed model proved to perform well to represent the effect of the confining pressure on damage evolution and permeability variations. The parametric study presented in the paper shows that softening is more likely to occur at high confining pressure. It has been possible to simulate the mean stress release after the peak of deviatoric stress, resulting in an increase of the average size of the natural pores.

The main advantages of the proposed framework are simplicity and versatility. The input parameters are easy to determine in the laboratory, and the permeability model can supplement any damage model based on Continuum Damage Mechanics. 
1. Abu Al Rub R, Voyiadjis GZ. On the coupling of anisotropic damage and plasticity models for ductile materials. Int. J. Solids A/ Struct. 2003; 40:2611-2643

2. Alkan H. Percolation model for dilatancy-induced permeability of the excavation damaged zone in rock salt. International Journal of Rock Mechanics and Mining Sciences 2009; 46: 716-724

3. Alves C,Sequeira Braga MA, Hammecker C. Water transfer and decay of granitic stones in monuments. C.R. Acad. Sci. Paris 1996; serie IIa (Surface Geosciences):397-402

4. Arson C, Gatmiri B. Numerical study of a thermo-hydro-mechanical model for unsaturated porous media. Annals of Solid and Structural Mechanics 2010; 1:(2):59-78

5. Auqu LF, Acero P, Gimeno MJ, Gomez JB, Asta MP. Hydrogeochemical Modeling of a Thermal System and Lessons Learned for CO2 Geologic Storage. Chemical Geology 2009; 268:324-336.

6. Basagaoglu H, Succi S, Manepally C, Fedors R, Wyrick DY. Sensitivity of the active fracture model parameter to fracture network orientation and injection scenarios. Hydrogeology Journal 2009; 17:13471358

7. Bera B, Bera M, Sushanta K, Vick D. Understanding the micro structure of Berea Sandstone by the simultaneous use of micro-computed tomography (micro-CT) and focused ion beam-scanning electron microscopy (FIB-SEM). Micron 2011; 42:(5):412-418

8. Blumling P, Bernier F, Lebon P, Martin CD. The excavation damaged zone in clay formations timedependent behaviour and influence on performance assessment. Physics and Chemistry of the Earth 2007; 32(8-14):588-599.

9. Bonin B. Deep geological disposal in argillaceous formations : studies at the Tournemire test site. J. of Contaminant Hydrology 1998; 35:315-330.

10. Bourdet D. Well Test Analysis: the use of advanced interpretation models. Elsevier, Amsterdam, The Netherlands 2002

11. Brandl H. Energy Foundations and Other Thermo-Active Ground Structures. Géotechnique 2006; 56:(2):81-122

12. Brooks RH, Corey AT. Properties of porous media affecting fluid flow. J. irrig. Drain. Div., Am. Soc. Civil. Eng. 1966; 92:61-88

13. Chan KS, Bodner SR, Munson DE. Permeability of WIPP Salt during Damage Evolution and Healing. International Journal of Damage Mechanics 2001; 10:347-375

14. Chiarelli AS, Shao JF. Modélisation élastoplastique couplée à l'endommagement anisotrope induit pour les argilites. Revue Française de Génie Civil 2000; 6:(1):115-130

15. Cordebois JP, Sidoroff F. Endommagement anisotrope en élasticité et plasticité. Journal de Mécanique théorique et appliquée 1982; special issue, 45-60

16. Corey AT. Measurement of water and air permeability in unsaturated soils. Soil Sci. Soc. Amer. Proc. 1957; 21:7-10

17. Cosenza P, Ghoreychi M. Evolution de la perméabilité du sel gemme sous solicitations mécano-chimiques. Bull. Soc. géol. France 1997; 168:(3):313-324

18. Cosenza P, Ghoreychi M, Bazargan-Sabet B, de Marsily G. In situ rock salt permeability measurement for long term safety assessment of storage. Int. J. Rock Mech. Min. Sci. 1999; 36:(4):509-526

19. Davidson P. A. Turbulence - An Introduction for Scientists and Engineers. Oxford University Press 2004

20. de Menezes JEQ, Nguyen Minh, D. Subsidence prediction above gas storage cavity fields. Numerical Models in Geomechanics - NUMOG VI, Proc. 6th International Symposium on Numerical Models in Geomechanics (NUMOG VI), Montreal, Canada, Jul. 02-04, 1997, Pietruszczak S. and Pande G.N. editors, Balkema 1997; 475-480

21. Durner W. permeability estimation for soils with heterogeneous pore structure. Water Resour. Res. 1994; 30(2):211-223

22. Dragon A, Halm D. Modélisation de l'endommagement par méso-fissuration : comportement unilatéral et anisotropie induite. C.R. Acad. Sci. Paris 1996; 322:275-282

23. Favre JL. Géotechnique. Sécurité des Ouvrages. Risques. Ellipses 2004.

24. Garcia-Bengoechea I, Lovell CW, Altschaeffl AG. Pore distribution and permeability of silty clays. $J$. Geotech. Eng. Div. 1979; 105:839-856.

25. Gens A, Garcia-Molina AJ, Olivella S, Alonso EE, Huertas F. Analysis of a full scale in situ test simulating repository conditions. International Journal for Numerical and Analytical Methods in Geomechanics 1998; 22:515-548.

26. Guéguen Y, Gravilenko P, Le Ravalec M. Scales of Permeability. Surveys in Geophysics 1996; 17:245-263

27. Hagoort J. Simulation of Production and Injection Performance of Gas-Storage Caverns in Salt Formations. SPE Reservoir Engineering 1994; 9:(4):278-282

28. Halm D, Dragon. Modélisation de l'endommagement par mésofissuration du granite. Revue Française de Génie Civil 2002; 6:(1):21-33

29. Hansen NR, Schreyer HL. A thermodynamically consistent framework for theories of elastoplasticity coupled with damage. Int. J. Solids and Structures 1994; 31:(3):359-389 
30. Homand F, Chiarelli A.S, Hoxha, D. Caractéristiques physiques et mécaniques du granite de la Vienne et de l'argilite de l'Est. Revue Française de Génie Civil 2002; 6:(1):11-20

31. Homand-Etienne F, Hoxha D, Shao JF. A continuum damage constitutive law for brittle rocks. Computers and Geotechnics 1998; 22:(2):135-151

32. Honarpour M, Koederitz L, Harvey, AH. Relative permeability of petroleum reservoirs, CRC Press, Inc. Boca Raton, Florida 1986

33. Ireson AM, Mathias SA, Wheater HS, Butler AP, Finch J. A model for flow in the chalk unsaturated zone incorporating progressive weathering. Journal of Hydrology 2009; 365:244-260

34. Kachanov M. Effective elastic properties of cracked solids: critical review of som basic concepts. Appl. Mech. Rev. 1992; 45:(8):304-335

35. Krajcinovic D. Damage Mechanics. North-Holland 1996

36. Lemaitre A, Desmorat R. Engineering Damage Mechanics. Ductile, creep, fatigue and brittle failure. Springer - Verlag, Berlin Heidelberg 2005

37. Levitz P. Toolbox for 3D imaging and modeling of porous media: Relationship with transport properties. Cement and Concrete Research 2007; 37:(3):351-359

38. Long JCS, Remer JS, Wilson CR, Witherspoon PA. Porous Media Equivalents for Networks of Discontinuous Fractures. Water Resources Research 1982; 18:(3):645-658.

39. Lund JW. Characteristics, Development and Utilization of Geothermal Resources. Geo-Heat Center Bulletin 2007; 28:(2):1-9

40. Maleki K. Modélisation numérique du couplage entre l'endommagement et la perméabilité des roches Application à l'étude des ouvrages de stockage souterrain. PhD Thesis, Ecole Nationale des Ponts et Chaussées 2004

41. Maleki K, Pouya A. Numerical Simulation of Damage-Permeability Relationship in Brittle Geomaterials. Computers and Geotechnics 2010; 37:619-628.

42. Mancktelow NS, Grujic D, Johnson, EL. An SEM study of porosity and grain boundary microstructure in quartz mylonites, Simplon fault zone, central Alps. Contributions to Mineralogy and Petrology 1998; 131:(1):71-85

43. Martino JB, Chandler NA. Excavation-induced damage studies at the Underground Research Laboratory. Int. J. Rock Mech. and Min. Sci. 2004; 41:1413-1426.

44. Narsilio GA, Buzzi O, Fityus S, Yun TS, Smith DW. Upscaling of Navier-Stokes equations in porous media: Theoretical, numerical and experimental approach. Computers and Geotechnics 2009; 36:(7):1200-1206

45. Olivella S, Gens A. Double structure THM analyses of a heating test in a fractured tuff incorporating permeability variations. International Journal of Rock Mechanics ES Mining Sciences 2005; 42:667-679

46. Peters RR, Klavetter EA. A Continuum Model for Water Movement in an Unsaturated Fractured Rock Mass. Water Resources Research 1988; 24:(3):416-430

47. Potyondy DO, Cundall PA. A bonded-particle model for rock. International Journal of Rock Mechanics and Mining Sciences 2004; 41:1329-1364

48. Pruess K, Wang JSY, Tsang YW. On thermohydrologic conditions near high-level nuclear wastes emplaced in partially saturated fractured tuff. 2. Effective continuum approximation. Water Resour. Res. 1990; 26(6):1249-1261.

49. Romero E. Characterisation and Thermo-Hydro-Mechanical Behavior of Unsaturated Boom Clay: an Experimental Study. PhD Thesis, Univertitat Politecnica de Catalunya, Barcelona 1999.

50. Rojas E, Gallegos G, Leal, J. A porous model based on porosimetry to simulate retention curves. Unsaturated Soils - Proc. of the 5th Int. Conf. on Unsaturated Soils, Barcelona, Spain, 6-8 september 2010, CRC Press, Alonso EE and Gens A editors 2011; 2:927-932

51. Russell AR. Fractals, double porosimetry and the soil-water characteristic curve. Unsaturated Soils Proc. of the 5th Int. Conf. on Unsaturated Soils, Barcelona, Spain, 6-8 september 2010, CRC Press, Alonso EE and Gens A editors 2011; 2:945-950

52. Rutqvist J, Borgesson L, Chijimatsu M, Hernelind J, Jing L, Kobayashi A, Nguyen S. Modeling of damage, permeability changes and pressure responses during excavation of the TSX tunnel in granitic rock at URL, Canada. Environmental Geology 2009; 57:1263-1274

53. Salgueiro R, Olivella S, Suriol J. Constitutive model developments for compacted unsaturated fine grained soils based on porosimetry. Unsaturated Soils - Proc. of the 5th Int. Conf. on Unsaturated Soils, Barcelona, Spain, 6-8 september 2010, CRC Press, Alonso EE and Gens A editors 2011; 2:951-956

54. Schulze O. Investigations on damage and healing of rock salt, in: The Mechanical Behavior of Salt Understanding the THMC Processes in Salt. Wallner, Lux Minkley $\&$ Hardy, Jr (eds), Taylor \& Francis Group, London 2007; 33-43

55. Shao JF, Zhou H, Chau KT. Coupling between anisotropic damage and permeability variation in brittle rocks. International Journal for Numerical and Analytical Methods in Geomechanics 2005; 29:12311247. 
56. Slizowski J, Walaszczyk J. Long term stability evaluation of natural gas storage caverns. Mineral Resources Management 2008; 24:(4-1):83-100

57. Souley M, Homand F, Pepa S, Hoxha D. Damage-induced permeability changes in granite: a case example at the URL in Canada. International Journal of Rock Mechanics and Mining Sciences 2001; 38:297-310

58. Tsang CF, Bernier F, Davies C. Geohydromechanical processes in the Excavation Damaged Zone in crystalline rock, rock salt, and indurated and plastic clays - in the context of radioactive waste disposal. Int. J. Rock Mech. and Min. Sci. 2005; 42:109-125.

59. Van Genuchten, M.T. A closed-form equation for predicting the permeability of unsaturated soils. Soil Science Society of America Journal 1980; 44:892-898.

60. Vogel T, Gerke HH, Zhang R, Van Genuchten MT. Modeling flow and transport in a two-dimensional dual-permeability system with spatially variable hydraulic properties. J. Hydrol. 2000; 238:78-89.

61. Xu T, Apps JA, Pruess K. Numerical Simulation of CO2 Disposal by Mineral Trapping in Deep Aquifers. Applied Geochemistry 2004; 19:917-936.

62. Zhao C, Hobbs BE, Hornby P, Ord A, Peng S. Numerical modelling of fluids mixing, heat transfer and non-equilibrium redox chemical reactions in fluid-saturated porous rocks, International Journal for Numerical Methods in Engineering 2006; 66:1061-1078.

63. Zhao C, Hobbs BE, Ord A, Hornby P, Peng S, Liu L. Mineral precipitation associated with vertical fault zones: The interaction of solute advection, diffusion and chemical kinetics, Geofluids 2007; 7:3-18.

64. Zhao C, Hobbs BE, Ord A. Convective and Advective Heat Transfer in Geological Systems, Springer, Berlin, 2008

65. Zhao C, Hobbs BE, Hornby P, Ord A, Peng S, Liu, L. Theoretical and numerical analyses of chemicaldissolution front instability in fluid-saturated porous rocks, International Journal for Numerical and Analytical Methods in Geomechanics 2008; 32(9):1107-1130.

66. Zhao C, Hobbs BE, Ord, A. Fundamentals of Computational Geoscience: Numerical Methods and Algorithms, Springer, Berlin, 2009.

67. Zhang H, Falcone G, Valko P, Teodoriu C. Numerical Modeling of Fully-Transient Flow in the NearWellbore Region During Liquid Loading in Gas Wells. 2009 SPE Latin American 83 Caribbean Petroleum Engineering Conference, 31-May-09 to 03-Jun-09, Cartagena, Colombia, SPE-122785

68. Zhou H, Shao JF, Feng XT, Hu DW. Coupling Analysis between Stress Induced Anisotropic Damage and Permeability Variation in Brittle Rocks. Key Engineering Materials 2007; 340-341:1133-1138

69. Zimmermann G, Burkhardt H, Engelhard L. Scale Dependence of Hydraulic and Structural Parameters in the Crystalline Rock of the KTB. Pure Appl. Geophys. 2003; 1601067-1085 